\title{
The South Africa Stress and Health Study: Rationale and Design
}

\author{
David R. Williams, ${ }^{1,6}$ Allen Herman, ${ }^{2}$ Ronald C. Kessler, ${ }^{3}$ John Sonnega, ${ }^{1}$ \\ Soraya Seedat, ${ }^{4}$ Dan J. Stein, ${ }^{4}$ Hashim Moomal, ${ }^{2}$ and Colwick M. Wilson ${ }^{5}$
}

Received November 4, 2003; accepted December 19, 2003

The South Africa Stress and Health Study (SASH) is a large psychiatric epidemiological survey that is currently underway in South Africa. It is a part of the World Health Organization's World Mental Health (WMH) 2000 initiative and seeks to complete interviews with a nationally representative sample of 5000 adults. The WMH initiative is obtaining population-based data on the prevalence and severity of specific psychiatric disorders, demographic and psychosocial correlates of these diagnoses, and the levels and adequacy of mental health service utilization. SASH is using the fully structured pencil and paper version of the WHO Composite International Diagnostic Interview (CIDI) to assess lifetime and 12-month rates of mental disorders using both the DSM-IV and the ICD-10 diagnostic systems. In addition, the SASH seeks to collect information on the prevalence of exposure to physical and psychological torture in South Africa and to assess the association between such traumas and specific psychiatric disorders. It will also assess a broad range of risk factors and resources that may modify the association between exposure to human rights violations and mental health.

Key words: Epidemiology; South Africa; torture; psychiatric disorders; mental health services.

\section{INTRODUCTION}

Understanding the psychological sequelae of exposure to torture and political violence is an important area of inquiry in the field of mental health (Basogulu et al., 1997; Piwowarczyk et al., 2000) in both the developed and the developing world (Desjarlais et al., 1995). Prior research suggests that individuals who were exposed to torture report elevated levels of physical (Foster, 1987; Goldfeld et al., 1988) and psychological (Basogulu et al., 1997; Niederland, 1981; Van Velsen et al., 1996) health problems. However, while useful, these studies are limited because of selection biases associated with the use of clinical and convenience samples.

The South Africa Stress and Health Study (SASH) has as its primary aim the systematic investigation of this timely and important topic in South Africa. Funded by the National

\footnotetext{
${ }^{1}$ Institute for Social Research, University of Michigan, Ann Arbor, Michigan.

${ }^{2}$ National School of Public Health, Medical University of South Africa, Republic of South Africa.

${ }^{3}$ Department of Health Care Policy, Harvard Medical School, Boston, Massachusetts.

${ }^{4}$ University of Stellenbosch, Republic of South Africa.

${ }^{5}$ Loma Linda University, Loma Linda, California.

${ }^{6}$ To whom correspondence should be addressed at Institute for Social Research, University of Michigan, P.O. Box 1248, Ann Arbor, Michigan 48106-1248. E-mail: wildavid@umich.edu
} 
Institutes of Health in the United States and sponsored by the World Health Organization (WHO), the SASH began in 1999 with the aim of interviewing 5000 adult South Africans from all provinces throughout the country to comprise a nationally representative sample. It is the first study of its kind to use a structured clinical interview in a national probability sample that also obtains prevalence estimates of exposure to torture. Elucidating the story of trauma and recovery in South Africa is important not only for its potential implications for program delivery in that country and for enhancing our scientific understanding, but also because it may have direct implications for our understanding of threats to the well-being of individuals in other countries around the world where multiple types of violence are rampant and institutionalized.

The SASH developed a new instrument designed to capture information about exposure to politically motivated physical and psychological torture and seeks to relate such experiences to the prevalence of psychiatric and substance use disorders that are assessed with a structured psychiatric diagnostic interview in the general population. Thus, the SASH will provide crucial new information about the prevalence of specific psychiatric disorders associated with all forms of political violence in South Africa. Given that this study includes a rich and varied set of information, the data obtained will be important in other respects as well. Some of these are outlined in the next section. This paper describes the rationale and design of this study and suggests some ways in which its findings will be useful to health researchers, practitioners, and policy makers.

\section{GOALS OF THE STUDY}

The SASH has a number of important goals and features that add to the significance of the data that will be obtained. First, as mentioned above, this study will provide unique information on the relationship between torture and mental health in South Africa. We completed extensive pilot work in the early years of the study (including in-depth qualitative interviews) to develop a scale to comprehensively capture exposure to physical and psychological torture during the apartheid era in South Africa, so that we could study the mental health consequences of such exposures. No representative general population data exist about the percent of South Africans whose daily lives were touched directly by apartheid nor about the distribution of traumatic events associated with racial-political violence. This study will provide a unique glimpse at the inter- and intragroup racial and ethnic differences in exposure to torture and its mental health consequences, as they are manifested in the context of a wide variety of stressors, coping resources, and individual help-seeking strategies of adults in South Africa.

Second, this study is one of the World Health Organization's World Mental Health (WMH) projects. The WMH initiative seeks to determine the global burden of mental disorders by assessing the prevalence and severity of specific psychiatric disorders and the levels and adequacy of service use, as well as identifying barriers to treatment. Key features of WMH include the use of a common instrument, a standardized translation protocol, standardized training of interviewers and the use of consistent field procedures in all participating countries. The SASH will provide, for South Africa, national estimates of the prevalence of specific psychiatric disorders, demographic and psychosocial correlates of these diagnoses, the level of impairment associated with specific disorders and the patterns 
and correlates of treatment. Such nationally representative data is seldom available in the developing world in general, and in Africa, in particular. This will allow comparison of our data with comparable information from over two dozen other countries in the world.

Third, the SASH has identical measures of mental health, some psychosocial resources and racial discrimination as the recently completed NIMH-funded National Study of American Life (NSAL) directed by James S. Jackson at the University of Michigan in the United States. The NSAL is a national adult sample of 3589 native-born blacks in the United States, 1604 blacks of Caribbean ancestry and 1006 non-Hispanic whites. It seeks to explore intraand intergroup racial and ethnic differences in mental disorders and services use. It also assesses a broad range of stressors, risk and resilient factors, and coping resources. Thus, this study will also allow for unique cross-national comparisons with the United States, in general, and the American black population in particular. South Africa appears to be an especially appropriate society for comparison to the United States. Both countries share a history of legally enforced racial inequality that endured into the twentieth century. However, today, both are multiracial industrialized democracies with constitutions that have repudiated the institutional racial discrimination of the past but with the striking persistence of racial residential segregation and racial discrepancies in socioeconomic and health status. At the same time, there are also striking differences between the two societies. U.S. blacks have had a much longer period of freedom from legally enforced segregation than their South African counterparts. In addition, in contrast to African Americans being a numerical minority in U.S. society, South African blacks at $79 \%$ of the population have electoral dominance but even more marked social and economic deprivation. Examining the nature, levels, social and psychological contexts of psychiatric disorders, and the mental health correlates of perceived discrimination in these two societies is an unprecedented opportunity to enhance our understanding of the conditions under which perceived discrimination is associated with mental health status.

Fourth, this study will provide needed information on the mental health consequences of the HIV/AIDS epidemic in the country of the world that has the highest prevalence of this disease. Our questionnaire includes a brief module of questions on AIDS that will provide national data on the perceived threat of HIV/AIDS, behavioral changes in response to this threat, past and expected participation in HIV testing, perceived personal vulnerability to HIV/AIDS, and personal knowledge of individuals who have AIDS and who have died of AIDS. These questions will provide a characterization of the population of South Africa regarding risks and knowledge of AIDS and also allow for important analyses of the current psychological impact of HIV/AIDS.

Fifth, the study will investigate the impact of the Truth and Reconciliation Commission (TRC). The TRC is a unique institution that was designed by the government of South Africa to promote national unity and reconciliation among all South Africans by providing an opportunity for full disclosure of the gross violations of human rights under apartheid. The proposed evaluation of the mental health effects of the TRC will have practical implications for South Africa as well as other countries. There are many other countries around the world that aspire the same kind of transition from sectarian violence to democratic rule that has been achieved in South Africa. Little data exist on what structures and processes may assist in ameliorating the lingering effects of trauma, and on how a country might help foster the transition by recognizing the mental health consequences of trauma (Kaminer et al., 2001). The comprehensive nationally representative assessment of the TRC proposed here will be 
of enormous significance in providing information on the effectiveness and mental health impact of this approach.

Sixth, the study will provide a unique glimpse of gender differences in mental health, as well as in stressors, trauma, and responses to them. South African society characterized by high levels of violence against women, especially rape and interpersonal violence within the family (Gilbert, 1996; Jewkes and Abrahams, 2002; Marais et al., 1999; Straker et al., 1996). Gender is associated with differential exposure to trauma, and may also be associated with more serious physical and psychological consequences (Seedat and Stein, 2000). However, the extent to which exposure to multiple forms of violence in South Africa is associated with differential vulnerability by gender, to specific psychiatric disorders has not yet been assessed in nationally representative population data.

\section{BACKGROUND}

\section{Racial and Political Violence and Mental Health}

The available literature shows that individuals exposed to torture report higher levels of physical health problems and somatic symptoms (Foster, 1987; Goldfeld et al., 1988; Piwowarczyk et al., 2000), as well as greater psychological distress and symptomotology (Basogulu et al., 1997; Niederland, 1981). Prior research indicates that the most common psychological effects of trauma include depression, aggression, and posttraumatic stress disorder (PTSD) (Singer et al., 1995: Turner and van Velson, 1990). The symptoms of PTSD in those exposed to torture remain high decades after the experience (Kuch and Cox, 1992; Orwid et al., 1995). However, our current knowledge base is limited. Prior research suggests that only a very small proportion of individuals who have been exposed to political violence report this to their health care providers (Carey et al., 2003; Eisenman et al., 2003).

Despite these studies, knowledge concerning the effects of torture is still insufficient (Kantemir, 1994). Most of the information available on torture and mental health outcomes is derived from small clinical samples or from samples of refugees seeking asylum outside of the country where the torture occurred. Results from the latter are confounded by selection factors that likely make refugees hardier than those who remain behind. Further, separating the effects of trauma due to political violence from the stress associated with refugee status is difficult. A strength of the SASH is the use of a large representative sample of individuals in their country of origin.

Studies examining the association between racial-political violence and mental health outcomes in South Africa are few in number, and mainly in younger populations. Exposures to violence such as intracommunity street battles and township raids by security forces have been found to be associated with psychological distress in children (Dawes, 1994) and teens (Mkhize, 1994; Straker et al., 1996). Symptoms of fear and anxiety were shown to be common among those experiencing this form of violence. While these studies show an association between political violence and distress, it is not clear whether there is longer duration of symptoms or more severe psychological impairment. Several researchers have cautioned against assumptions of lasting impairment because of exposure to political violence and repression (Levett, 1989; Straker, 1989; Swartz, 1988; Swartz and Levett, 1989). The TRC hearings themselves also raised the question of the inevitability of severe psychological sequelae of human rights violations (Stein, 1998). 
One population-based study of adults in South Africa has examined the association of the most severe form of political violence-torture-with emotional difficulties (Hirschowitz and Orkin, 1997). A sample of 4000 South Africans were interviewed concerning lifetime traumatic events such as fighting a war, being attacked or witnessing an attack, being raped, participating in violence, being tortured, or losing one's home. Almost a quarter of the sample had been exposed to at least one of the traumas asked about in the survey. Of those exposed, $60 \%$ of whites, $71 \%$ of Indians, $74 \%$ of Coloreds, and $85 \%$ of Africans had experienced at least one PTSD symptom. However, the assessment of both trauma and mental health status was relatively narrow in this survey. The study did not provide a diagnosis of PTSD or include other mental health diagnostic categories known to be strongly associated with trauma in other studies, such as major depression, generalized anxiety disorder, panic disorder, or social phobia (Kessler et al., 1997; Marais et al., 1999). The SASH will correct this problem by including an assessment of mental health disorders utilizing the World Health Organization (WHO) Composite International Diagnostic Interview (CIDI) (WHO, 1997).

Inadequate research attention has been given to the effects that torture might have on an individual's social network and community. The effects of torture reach beyond the survivors themselves to their other family members and children (Foster, 1987). It is possible that the detrimental psychological impact of racial-political violence extends well beyond the victims themselves, and may lead to clinically significant psychiatric disorders in much of the community. The SASH will address this issue by assessing the impact of political violence on the close friends and relatives of victims of the focal respondent.

Another neglected aspect of the network impact of torture is how violence affects the mental health of the perpetrators (Kaminer and Stein, 2001). South African police working in the townships report a high level of stress-related disorders (Kale, 1995), and some evidence suggests that those individuals charged with suppressing resistance show heightened psychological distress and elevated rates of disorder (Dawes, 1990; Seedat et al., 2003). The SASH will elicit information not only about victimization but also perpetration of racialpolitical violence. Relatedly, the impact of violence, both as perpetrator and witness, on the white population in South Africa has also been overlooked in previous work (Dommisse, 1986). Anecdotal evidence suggests that witnessing political violence, having a friend or family member participate in violent acts, and dealing with the moral issues inherent in apartheid may all impact the psychological health of whites (Dawes, 1990; Seedat and Stein, 2001). There is little known about what kinds of psychopathology lead to perpetration (Kaminer and Stein, 2001) or about the effects of apartheid on the mental health of the white population (Kale, 1995). The SASH will provide valuable information on this topic.

Overall, the existing knowledge of the health consequences of exposure to racialpolitical violence in South Africa is limited. There is little available data on the association between politically motivated violence and mental health in South Africa (Gilbert, 1996; Kaminer and Stein, 2001), making health policy decisions difficult. Further, epidemiologic information concerning the mental health profile of South Africans has come from some rigorous but small scale studies (e.g., Rumble et al., 1996). The general rates, nature, and duration of violence potentially related to diagnoses such as PTSD, major depression, and generalized anxiety disorder are currently unclear. Studies are needed in South Africa that use standardized diagnostic criteria to assess PTSD and mental health status (Carey et al., 2003; Kantemir, 1994; Marais et al., 1999;). Findings from other countries may not be 
applicable to the transitional environment in South Africa. It is important that the stress associated with racial and political violence be placed in a social contextual model that accounts for a myriad of potential influences on both the events and outcomes.

\section{Racial Political Stress in Context: Potential Moderators}

There are a wide array of factors that can modify the associations between stress exposure and subsequent mental health outcomes. It is important to situate political violence within the social context of the environment. The SASH will do this by examining a wide range of vulnerability and resistance factors based on a stress-diathesis model. Characteristics both internal to the individual (e.g., personality, age, gender) and external to the individual (e.g., other stressors, social support) are hypothesized to influence the psychological impact of being a victim of or witnessing violence.

It is important to attend to structural dimensions such as age, gender, and race in examining exposure to trauma and subsequent mental health. South African males were found more likely than their female peers to experience at least one traumatic event in their lifetime (Hirschowitz and Orkin, 1997) and were more likely to be victimized in the street rather than the home. Women, on the other hand, report high levels of rape and interpersonal violence (Gilbert, 1996; Jewkes and Abrahams, 2002; Oloruntimehin, 1996). Women may also have higher levels of mental health problems associated with exposure to torture than do men (Carmil and Carel, 1986; Seedat and Stein, 2000).

Age at the time of exposure can also influence the reaction to violence (Dawes, 1994; Gibson, 1990; Singer et al., 1995) with children being at the greatest risk. It may be important to distinguish period effects from age in South Africa. Young people from the most violent period in South African history have stated that violence was not a problem in their society (Straker et al., 1996) and appear to have normalized their experiences of exposure to high levels of violence. Other data suggest that there is considerable distress among children and adolescents exposed to violence (Ensink et al., 1997).

Racial differences in exposure and vulnerability to trauma may play an important role in South Africa. The opportunity to examine the residual wounds of apartheid in this unique setting is unprecedented. In South Africa, there has been a rapid and uncontrolled urbanization of the black population. According to the 2001 South Africa Census, $16 \%$ of the population lives in urban shack settlements, areas that have been characterized by high levels of violence (Gilbert, 1996). Hirschowitz and Orkin (1997) found that although Africans and Indians reported lower proportions of exposure to traumatic events than whites and Coloreds, black South Africans reported higher levels of PTSD symptoms than all other groups.

Protective or resiliency factors in psychological reactions to political violence have not been adequately explored in South Africa (Dawes, 1994). Social support and extended family networks may serve to build resilience and lessen the psychological impact of exposure to trauma (Dawes, 1994). Confiding in others about the experience of victimization (Pennebaker and O'Herron, 1984), or providing therapy in public forums such as the TRC hearings may facilitate recovery (Stein, 1998). Factors within the individual, such as personality or coping style, may also serve to moderate the relationship between exposure and distress. 
Religious or political beliefs can also enhance the ability of an individual to handle trauma and violence (Dawes, 1994; Pargament, 1997). Research in the Middle East (Punamaki, 1987) and Cambodia (Kinzie et al., 1986) and South Africa (Basogulu et al., 1997) shows that religious and political belief systems reduce the negative effects of exposure to political violence. A South African study found that idealization of a fallen figure can reduce the psychological impact of a death (Dawes, 1994). The concept of forgiveness, a key aspect of religious practice, may be an important moderator of the impact of trauma (Kaminer et al., 2000). Among those who have experienced political violence, a common desire is for revenge and retribution. These feelings can be intensified if the perpetrator does not receive punishment commensurate with the crime or fails to show remorse (Wortman et al., 1997). Forgiveness involves the willingness to let go of these negative feelings. In the context of apartheid in South Africa, forgiveness may play a particularly important role in influencing the psychological reaction to political violence (Ogden et al., 2000).

Exposure to political violence and torture should also be situated within the social context of other acute and chronic stressors. The impact of racial and political violence may be affected by the occurrence of other events, both positive and negative. For example, chronic stressors like economic hardship and experiences of everyday discrimination may contribute to an individual's inability to cope with political violence. Similarly, acute stressors such as illnesses and disease or criminal victimization may alter the way an individual responds to the stress of violence. Another significant contextual stressor in South Africa is HIV/AIDS, which has exacted a heavy toll on the society. South Africa now accounts for more than $50 \%$ of the new cases of HIV in sub-Saharan Africa (UNAIDS, 2002). It is estimated that at least $10 \%$ of South Africans, or about 4 million people, are HIV positive. HIV/AIDS may thus be a new and major stressor that has important consequences for the mental health status of the South African population.

Another social factor that might modify the association between stress exposure and mental health is racism. The SASH provides a unique opportunity to examine the extent to which racism and nonmembership in the valued societal culture exacerbate the effects of exposure to violence on mental health. Recent research in the United States indicates that experiences of discrimination, both chronic and acute, are a stressor that adversely affects the mental health of racial minorities (Williams et al., 2003; Williams and Williams-Morris, 2000). Further, there is evidence from the United States that internalized racism — endorsing the dominant society's negative beliefs about one's group—is associated with mental health difficulties (Williams and Williams-Morris, 2000). In all probability South African blacks experience similar or heightened processes related to racism, but this likelihood has seldom been explored (Dommisse, 1986), particularly on a national scale. The SASH seeks to examine how a set of race-related stressors and vulnerabilities combines with more traditional measures of stress and exposure to political violence, both additively and interactively, to affect mental health. This has not been previously done in a systematic way with national data.

The SASH will carefully examine a diverse set of stress-diathesis variables that may modify the association of exposure to violence and subsequent mental health. These will include both resiliency and vulnerability factors. The influence of the multiple dimensions will be taken into account: the nature of the events themselves, factors internal to the individual, the interpersonal surroundings, and the larger sociopolitical environment. 


\section{METHODS}

The SASH received its initial funding from the National Institute of Mental Health (5 RO1 MH-59575). Supplemental support has been received from the National Institute of Drug Abuse in the United States and the Department of Mental Health of the Ministry of Health in South Africa. The collaborating investigators include David R. Williams (Principal Investigator, University of Michigan), Ronald C. Kessler (Co-Principal Investigator, Harvard University), Allen Herman (Co-Principal Investigator, Medical University of Southern Africa [MEDUNSA]), Dan Stein (Co-Principal Investigator, University of Stellenbosch), Hashim Moomal (Investigator, MEDUNSA), and Soraya Seedat (Investigator, University of Stellenbosch). Human Subjects committees of the University of Michigan, Harvard Medical School, and MEDUNSA approved the recruitment, consent, and field procedures. The SASH began initial work with MarkData. However, all of the fieldwork for the survey is currently being done by CASE (Community Agency for Social Enquiry). CASE is directed by Dr. Zaid Kimmie and it has conducted several large national probability studies in South Africa.

\section{Sample Selection}

The SASH participants will be a nationally representative sample of 5000 individuals age 18 and above. The national sample is a multistage, area probability sample of adults living in both households and hostel quarters. Many economically active males live in grouphostel quarters in South Africa. Sampled residences were stratified into 10 diverse housing categories: Rural-commercial, agricultural, rural traditional subsistence areas, African townships, informal urban or peri-urban shack areas, Colored townships, Indian townships, general metropolitan residential areas, general large metropolitan residential areas, and domestic servant accommodation in urban areas. Within each of these strata, 600 households were listed from maps, census data, or aerial photographs. A probability sample of households was selected and screened to determine eligibility. A single adult respondent from each selected dwelling was drawn radomly using the Kish method.

\section{Fieldwork}

In the early years of the study, we conducted extensive pilot work to develop a scale to capture exposure to physical and psychological torture during the apartheid era that was relevant to South Africa. To elicit detailed information about the experiences of apartheid, indepth interviews were conducted with 90 South Africans from diverse backgrounds. Content analysis was used to analyze the themes of these interviews and a formal interview with structured questions was created. The development of this instrument was also informed by reading transcripts of the TRC hearings. The structured interview was then readministered to many of the same respondents to clarify any difficulties.

The questions developed for South Africa were then combined with the WMH paper and pencil instrument. Following the WMH translation protocol, the questionnaire was translated and back-translated. The interview was scripted in six different languages: English, 
Afrikaans, Zulu, Xhosa, Northern Sotho, and Tswana. Virtually all South Africans speak at least one of these languages. Two formal pretests of all of the survey questions were completed with a total of over 50 respondents participating. The length of the instrument emerged as a major problem in this preliminary work and some questions, including entire modules of the WMH paper and pencil instrument questionnaire were dropped from SASH in an effort to shorten the questionnaire.

We completed training for the interviewer supervisors of the CASE survey firm in November 2001 and the data collection for the main survey began in earnest in January 2002. The data collection has been proceeding province by province with a cohort of 4060 interviewers being trained in each province. All interviewers are trained in centralized, group sessions lasting 1 week. Only interviewers who demonstrated that they have mastered the administration of the survey instrument by the end of training are allowed to work in the field. Fieldwork supervisors play a critical role in the selection of households and selected respondents. A supervisor visits each selected enumeration area (EA), does a physical count of the residences, randomly select the sample houses for that EA, and participates with the interviewer with the in listing the residents at that dwelling and selecting the sampled individual. At this point informed consent is obtained (if the designated respondent is available) and an appointment time is scheduled for the interview. The interviewer then goes to the selected individual to complete the interview. The interview is averaging about $3 \mathrm{~h}$ in length, with some respondents requiring a second visit for completion of the interview.

\section{Data Management}

The fieldwork in SASH utilized the paper and pencil version of the WMH-CIDI. Data entry will be done by the survey research firm in South Africa. Once the data are entered and verified it will be transferred to the University of Michigan and Harvard University for post processing. Imputation of missing data and creation of scales and WMH-CIDI diagnoses will be done at this time. Nonresponse and sampling design adjustment weights will be added to the data set and entered into a codebook.

\section{Instrumentation}

The instrument used in the SASH is the World Mental Health pencil and paper version of the WHO Composite International Diagnostic Interview (WMH-CIDI; WHO, 1997) to assess mental disorders. Diagnoses will be made using both the DSM-IV (American Psychiatric Association, 1994) and ICD-10 (CIDI; WHO, 1991) diagnostic systems. The CIDI is a fully structured interview designed to be used by trained interviewers who do not have clinical experience. Lifetime and 12-month versions of the following disorders were assessed in SASH: major depression, panic, social phobia, agoraphobia, generalized anxiety disorder, intermittent explosive disorder, suicidality, substance use, premenstrual syndrome, and PTSD. Screening questions for personality disorders and psychosis were also included. In addition, measures of role impairment and disability developed by the WHO were included. Measures of impairment will provide information regarding the seriousness of untreated mental disorders, and may be used as a needs assessment for South 
African health systems. Several questions required minor modification for use in South Africa. A small number of non-WMH questions were added to the questionnaire because of their relevance to the South African context. These include questions about neighborhood context, perceptions of discrimination, HIV/AIDS, and psychosocial risks and resources: self-esteem, hopelessness, mastery, goal striving stress, and John Henryism (James, 1994).

As noted, an important part of SASH was the development of measures of exposure to human rights violations, and perceptions of the TRC based on our extensive pilot work. The human rights violation scale developed assesses specific experiences that respondents may have encountered because of their political activities while living as a civilian (physically beaten, attacked by dogs, etc.), and incidents that occurred among those who were ever in custody (electric shocks, poisoning, sleep deprivation, etc.). Questions also assess exposure to psychological torture (e.g., given false information about a family member) and torture experienced by immediate family members or very close friends because of the respondents political activities. A final section of the human rights violations scale ask respondents whether they had ever been a perpetrator of a range of specific human rights violations because of their job or for political reasons. The questions about the TRC begin with asking respondents about their perceptions of the benefits of the TRC when its work began. Additional items query direct involvement with the TRC and evaluation of those experiences, as well as whether there were any relevant personal experiences that had not been shared with the TRC. Questions also assess the role of significant others in encouraging or discouraging TRC participation and general perceptions of benefits of the TRC for victims, perpetrators, and the larger society.

\section{Clinical Reappraisal Interviews}

Given that the CIDI has not been previously administered in a general population sample of South Africa, it is important to carry out parallel validation interviews to evaluate the diagnoses obtained with this instrument. To that end 100 respondents in the main survey are being reinterviewed by a clinician who is blind to their CIDI responses. The semi-structured SCID diagnostic interview will be used to generate DSM and ICD diagnoses. In selecting respondents for the reappraisal sample, we oversample participants who met criteria for PTSD, GAD, major depression, agoraphobia, social phobia, and substance disorder. Clinical reappraisal interviews will also be completed with 20 respondents who did not screen into any of the targeted CIDI diagnostic sections.

\section{CURRENT STATUS}

As of the middle of December, 2003, we have completed almost $80 \%$ of our target of 5000 interviews. Interviewing is on-going in the following provinces: Free State, Northern Cape, Mpumalanga, and Western Cape. The level of cooperation has been extraordinarily high with very few selected respondents refusing to participate in the study. We anticipate completing all of the fieldwork for both the main survey and the clinical reappraisal interviews by February, 2004. 


\section{CONCLUSION}

No prior studies have concurrently measured rates of psychological distress and serious mental disorders along with exposure to physical and psychological torture in a large, heterogeneous, representative national sample in the country where the trauma occurred. Thus, the SASH has implications for the study of torture and mental health globally. The study results will also be indispensable for understanding potential mental health sequelae of such trauma at a very detailed level. The range of diathesis variable available in SASH will also allow for a comprehensive exploration of the context and course of mental illness. In addition, in one of the countries in the world hardest hit by HIV/AIDS, it will provide a unique glimpse of the mental health consequences of this epidemic.

The results of this study may also be of great importance to the South African government. It will provide the South African Department of Health with the first nationally representative data on the magnitude and distribution of the mental health disorders. It will also provide currently unavailable data on patterns and correlates of service use and barriers to obtaining available treatment. The results from this study could have major effects on the direction of mental health care policy planning efforts over the next decade.

\section{ACKNOWLEDGMENTS}

Preparation of this paper was supported by grant MH59575 from the National Institute of Mental Health and the National Institute of Drug Abuse.

\section{REFERENCES}

American Psychiatric Association (1994). Diagnostic and Statistical Manual of Mental Disorders—Fourth Edition, American Psychiatric Press, Washington, DC.

Basogulu, M., Mineka, S., Paker, M., Aker, T., Livanou, M., and Gok, S. (1997). Psychological preparedness for trauma as a protective factor in survivors of torture. Psychol. Med. 27:1421-1433.

Carey, P., Stein, D.J., Zungu-Dirwayi, N., and Seedat, S. (2003). Trauma and posttraumatic stress disorder in an urban xhosa primary care population: Prevalence, comorbidity, and service use patterns. J. Nerv. Ment. Dis. 191:230-236.

Carmil, D., and Carel, R. (1986). Emotional distress and satisfaction in life among Holocaust survivors-a community study of survivors and controls. Psychol. Med. 16:141-149.

Dawes, A. (1990). The effects of political violence on children: A consideration of South African and related studies. Int. J. Psychol. 25:13-31.

Dawes, A. (1994). Childhood and Adversity: Psychological Perspectives From South African Research, David Philip, Claremont, South Africa.

Desjarlais, R.R., Eisenberg, L., Good, B., and Kleinman, A. (1995). World Mental Health: Problems and Priorities in Low-Income Countries, University of Oxford Press, Oxford.

Dommisse, J. (1986). The psychological effects of apartheid psychoanalysis: Social, moral and political influences. Int. J. Soc. Psychol. 32:51-63.

Eisenman, D.P., Gelberg, L., Liu, H., and Shapiro, M.F. (2003). Mental health and health-related quality of life among adult Latino primary care patients living in the United States with previous exposure to political violence. JAMA 290:667-670.

Ensink, K., Robertson, B.A., Zisis, C., and Leger, P. (1997). Post-traumatic stress disorder in children exposed to violence. South Afr. Med. J. 87:1526-1530.

Foster, D. (1987). Detention and Torture in South Africa: Psychological, Legal and Historical Studies, David Philip, Capetown, South Africa.

Gibson, K. (1990). Case studies of children in political violence. In (N.D. Manganyi and A. Du Toit, eds.), Political Violence and the Struggle in South Africa, Macmillan Press, London. 
Gilbert, L. (1996). Urban violence and health: South Africa, 1995. Soc. Sci. Med. 43:873-886.

Goldfeld, A., Mollica, R., Persavento, B., and Faraone, S. (1988). The physical and psychological sequelae of torture. JAMA 259:2725-2729.

Hirschowitz, R., and Orkin, M. (1997). Trauma and mental health in South Africa. Soc. Indicators Res. 41:169-182. James, S. (1994). John Henryism and the health of African Americans. Culture Med. Psychiatry 18:163-182.

Jewkes, R., and Abrahams, N. (2002). The epidemiology of rape and sexual coercion in South Africa: An overview. Soc. Sci. Med. 55:1231-1244.

Kale, R. (1995). New South Africa's mental health. BMJ 310:1254-1256.

Kaminer, D., and Stein, D.J. (2001). Sadistic personality disorder in perpetrators of human rights abuses: A South African case study. J. Pers. Disord. 15:475-486.

Kaminer, D., Stein, D.J., Mbanga, I., and Zungu-Dirwayi, N. (2000). Forgiveness: Toward an integration of theoretical models. Psychiatry 63:344-357.

Kaminer, D., Stein, D.J., Mbanga, I., and Zungu-Dirwayi, N. (2001). The truth and reconciliation commission in South Africa: Relation to psychiatric status and forgiveness among survivors of human rights abuses. $\mathrm{Br}$. $J$. Psychiatry 178:373-377.

Kantemir, E. (1994). Studying torture survivors: An emerging field in mental health. JAMA 272:400-401.

Kessler, R.C., Davis, C.G., and Kendler, K.S. (1997). Childhood adversity and adult psychiatric disorder in the U.S. National Comorbidity Survey. Psychol. Med. 27:1101-1119.

Kinzie, J.H., Sack, W.H., Angell, W.H., Manson, S., and Rath, B. (1986). The psychiatric effects of massive trauma on Cambodian children: 1. The children. J. Am. Acad. Child Adolesc. Psychiatry 25:370-376.

Kuch, K., and Cox, B. (1992). Symptoms of PTSD in 124 survivors of the Holocaust. Am. J. Psychiatry 149:337340.

Levett, A. (1989). Psychological trauma and childhood. Psychol. Soc. 12:19-32.

Marais, A., de Villiers, P.J., Mollder, A.T., and Stein, D.J. (1999). Domestic violence in patients visiting general practitioners-prevalence, phenomenology, and association with psychopathology. South Afr. Med. J. 89:635640.

Mkhize, H. (1994). Violent oppression: Implications for mental health priorities in South Africa. Med. Law 13:193-203.

Niederland, W. (1981). The survivor syndrome: Further observations and dimensions. J. Am. Psychoanal. Assoc. 29:413-425.

Ogden, C.J., Kaminer, D., Van Kradenburg, J., Seedat, S., and Stein, D.J. (2000). Narrative themes in responses to trauma in a religious community. Cent. Afr. J. Med. 46:178-184.

Oloruntimehin, O. (1996). Urban violence: Health consequences and costs. Soc. Sci. Med. 43:887-888.

Orwid, M., Domagalska, K., and Pietruzewski, K. (1995). The psychosocial effects of the Holocaust on Jewish survivors living in Poland. Psychiatr. Pol. 29:29-48.

Pargament, K. (1997). The Psychology of Religion and Coping: Theory, Research, Practice, Guilford Press, New York.

Pennebaker, J.W., and O'Herron, R.C. (1984). Confiding in others and illness rate among spouses of suicide and accidental-death victims. J. Abnorm. Psychol. 93:473-476.

Piwowarczyk, L., Moreno, A., and Grodin, M. (2000). Health care of torture survivors. JAMA 284:539-541.

Punamaki, R.L. (1987). Content of and factors affecting coping modes among Palestinian children. Scand. J. Dev. Altern. 6:86-98.

Rumble, S., Swartz, L., Parry, C., and Zwarenstein, M. (1996). Prevalence of psychiatric morbidity in the adult population of a rural South African village. Psychol. Med. 26:997-1007.

Seedat, S., Le Roux, C., and Stein, D.J. (2003). Prevalence and characteristics of trauma and post-traumatic stress symptoms in operational members of the South African National Defense Force. Mil. Med. 168:71-75.

Seedat, S., and Stein, D.J. (2000). Trauma and post-traumatic stress disorder in women: A review. Int. Clin. Psychopharmacol. 15(Suppl.):S25-S33.

Seedat, S., and Stein, M.B. (2001). Post-traumatic stress disorder: A review of recent findings. Curr. Psychiatry Rep. 3:288-294.

Singer, Z., Anglin, T.M., Song, L., and Lunhofer, L. (1995). Adolescents' exposure to violence and associated symptoms of psychological trauma. JAMA 273:477-482.

Stein, D.J. (1998). Psychiatric aspects of the Truth and Reconciliation Commission in South Africa. Br. J. Psychiatry 173:455-457.

Straker, G. (1989). From victim to villain: A slight of speech? Media representations of township youth. S. Afr. J. Psychol. 19:20-27.

Straker, G., Mendelsohn, M., Moosa, F., and Tudin, P. (1996). Violent political contexts and the emotional concerns of township youth. Child Dev. 67:46-54.

Swartz, L. (1988). The effects of repression on children. A review of some local work and some questions. In (C.P. Owen, ed.), Towards a National Health Service, Proceedings of the National Medical and Dental Association Conference, NAMDA Publications, Capetown, South Africa. 
Swartz, L., and Levett, A. (1989). Political repression and children in South Africa: The social construction of damaging effects. Soc. Sci. Med. 28:741-750.

Turner, S., and Van Velson, C. (1990). Victims of torture. Br. J. Hosp. Med. 44:345-346.

UNAIDS Joint United Nations Programme on HIV/AIDS (2002). South Africa: Epidemiological Fact Sheets on HIV/AIDS and Sexually Transmitted Infections, UNAIDS, Geneva, Switzerland.

Van Velsen, C., Gorst-Unsworth, C., and Turner, S. (1996). Survivors of torture and organized violence: Demography and diagnosis. J. Trauma Stress 9(2):181-193.

Williams, D.R., Neighbors, H.W., and Jackson, J.S. (2003). Racial/ethnic discrimination and health: Findings from community studies. Am. J. Public Health 93:200-208.

Williams, D.R., and Williams-Morris, R. (2000). Racism and mental health: The African American experience. Ethn. Health 5:243-268.

World Health Organization (1991). International Classifications of Diseases (ICD-10), World Health Organization, Geneva, Switzerland.

World Health Organization (1997). Composite International Diagnostic Interview (CIDI, Core Version 2.1), World Health Organization, Geneva, Switzerland.

Wortman, C.B., Battle, E.S., and Lemkau, J.P. (1997). Coming to terms with the sudden traumatic death of a spouse or child. In (R.C. David, A.J. Lurigio, and W.G. Skogan, eds.), Victims of Crime, 2nd ed., Sage, London, pp. $108-133$. 